\title{
Cervical dystonia associated with cavernous angioma of the frontal lobe
}

\author{
Belenky Vadim Victorovich", Voitsitsky Anatolii Nikolaevich \\ Neurology Clinic of Dr. Voitsitsky, St. Petersburg, Russia; ${ }^{*}$ Corresponding Author: vadimbele@yahoo.com
}

Received 10 April 2013; revised 11 May 2013; accepted 1 June 2013

Copyright (c) 2013 Belenky Vadim Victorovich, Voitsitsky Anatolii Nikolaevich. This is an open access article distributed under the Creative Commons Attribution License, which permits unrestricted use, distribution, and reproduction in any medium, provided the original work is properly cited.

\begin{abstract}
Structural lesions of CNS, reported to be associated with torticollis, are mostly restricted to cerebellum, brain stem and basal ganglia. In fact, we know only about two documented frontal lobe mass lesions-meningiomas, associated with torticollis. Our observation of frontal lobe cavernous angioma associated with clinical picture of torticollis confirms the role this area could play in the pathophysiology of involuntary movements. We report a case of patient with torticollis associated with cavernous angioma of the right frontal lobe and presuppose causative role of angioma in the development of our patient's torticollis.
\end{abstract}

Keywords: Cervical Dystonia; Cavernous Angioma; Meningioma

\section{INTRODUCTION}

Torticollis is the most common form of the focal dystonias. It is characterized by abnormal head movements and/or postures due to involuntary contractions of cervical muscles. The majority of cases are idiopathic. Secondary dystonia has been associated with a wide variety of vascular, traumatic, infectious, oncologic and toxic processes affecting the central nervous systems. Significant breakthrough in the genetics of dystonia, which took place in the last two decades, has not yet advanced much our understanding of pathophysiology of the torticollis. We still acquire knowledge of brain areas, responsible for control of voluntary neck movements, from secondary cases of cervical dystonia. According to LeDoux [1], the largest percentage of 25 cases of secon-

\footnotetext{
*Dr. Vadim Belenky and Prof. Voit report no financial support. Authors report no conflict of interest concerning the materials or methods used in this study or the findings specified in this paper.
}

dary cervical dystonia was associated with structural lesions of the brainstem (medulla, pons) and/or cerebellum (44\%). There were cases of single midbrain lesion and frontal lobe meningioma [2]. The remaining lesions were equally divided between the cervical spinal cord (24\%) and basal ganglia (24\%). In addition to aforementioned review we have found one more report [3] of cortical lesion associated with secondary torticollis. It was also meningioma, localized in the frontal lobe. In this paper we report the third case of lesion, associated with secondary cervical dystonia. It is cavernous angioma, localized, as in the two previous cases, in the frontal lobe.

\section{CASE REPORT}

Patient L., 50, female developed involuntary neck twisting on the right side at the age of 42, short after emotional stress-loss of her parents, and was hospitalized into neurology department of St. Petersburg medical academy of postgraduate education. She denied any other concomitant disorders except severe chronic bronchitis. In her family anamnesis it's necessary to point out her sister's breast carcinoma and her mother's kidney disease. Upon examination: Head was constantly twisted to the right with a slight clonic component, but the patient could turn it back voluntary. The hyperkinesis ameliorated with flank walking to the left and back and running ahead. There was a postural tremor in the right hand. Face was symmetrical, eyes movement were normal, face muscles were normal, tongue was with a slight deviation to the right. Biceps and triceps tendon reflexes to the left were stronger than to the right. Tendon reflexes from the legs were normal. There was a positive Babinsky sign from the right side. There were positive Wartenberg and Rossolimo signs. Muscle tonus was increased in the right hand on pyramidal type. Finger-nose probes were with slight intentional tremor, the patient was stable in simple Romberg position and deviated to 
the right in special Romberg position. Her plasma ceruloplasmin and cuprum were normal.

MRI of the brain demonstrated a foreign tissue growth with clear uneven outlines in basal area of the right frontal lobe. It was oval in shape, of nonhomogeneous structure, marked by isohyperintense signal on T1 and T2 weighted images, and peripheral circular hemosiderin deposits. Neither signs of perifocal edema nor extensional impact on adjacent structures have been detected. The size of the lesion was $16 \times 5 \times 18 \mathrm{~mm}$ (Figure 1). MRI angiography was normal.

In 2008 we recruited her for study of catecholamines

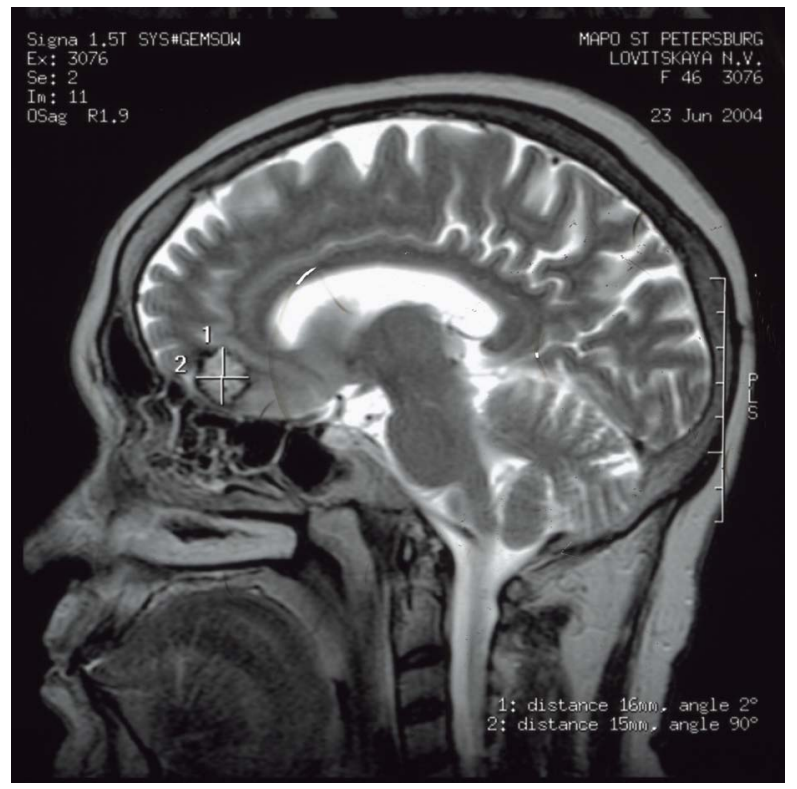

(a) and serotonin blood and urine level as well as other dystonic patients from our monitoring group. Her plasma serotonin level appeared to be decreased $(3.3 \mathrm{ng} / \mathrm{ml}$, norm $33 \mathrm{ng} / \mathrm{ml}$ - $82 \mathrm{ng} / \mathrm{ml}$ ) in contrast to patients with primary cervical dystonia, whose serotonin turnover proved to be substantially increased. We did not notice major signs of depression at that time. When we decided to publish her case recently and were about to ask her permission to be shot in the video , we were told by her neighbor that she had died after falling out of the window of her flat on the fifths floor.

In all 3 cases of cortical pathology, associated with

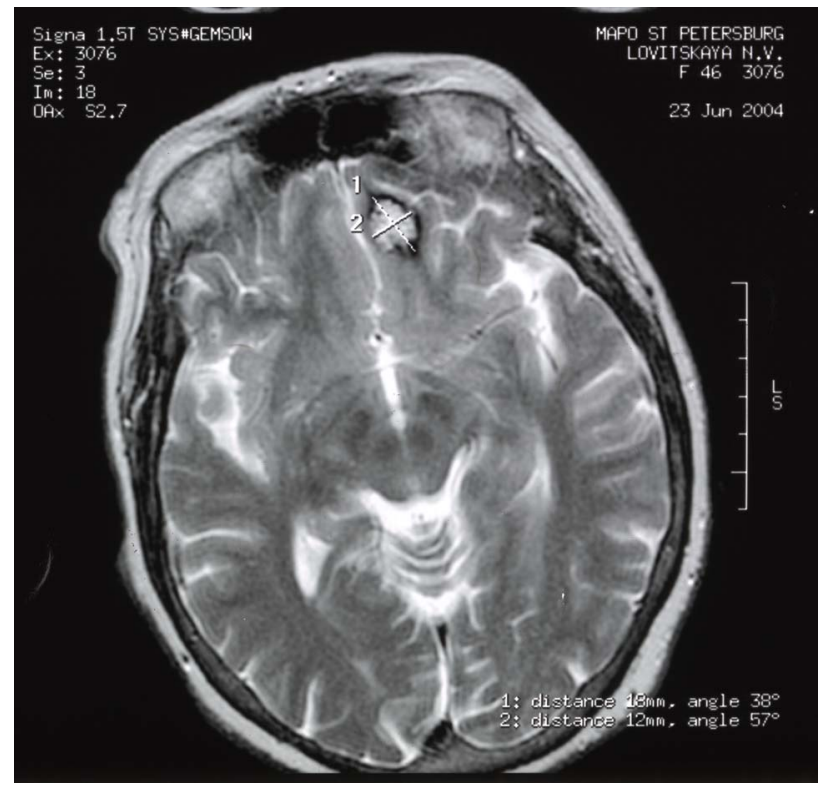

(b)

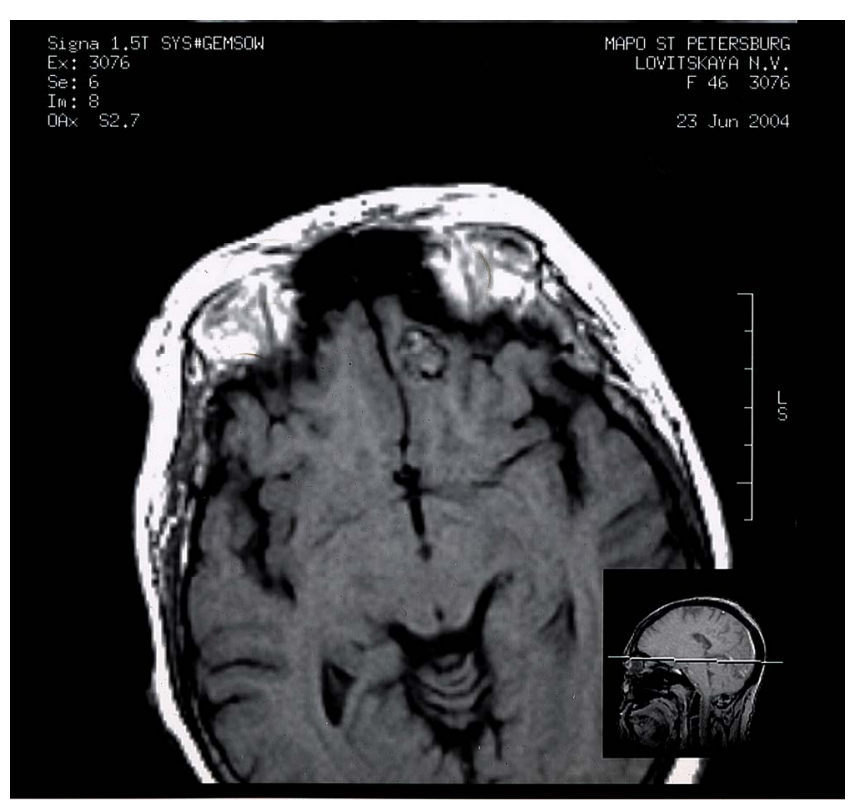

(c)

Figure 1. MRI of patient L. with cervical dystonia. 
secondary cervical dystonia, lesion was localized in the frontal lobe. By summing two additional cases with those reviewed by LeDoux, we could estimate, that frontal cortex is compromised in $11 \%$ of secondary dystonia, and this fact attests to the potential role of the area in the pathophysiology of primary cervical dystonia. There is some evidence to that in the data of other methods of brain investigation [4]. Kaste in 1981 reported cortical atrophy of frontoparietal area revealed by pneumoencephalography in 10 of the 13 patients with spasmodic torticollis [5]. Hypometabolism of glucose in frontal ortex and striatum in dystonic patients was demonstrated by PET with 18F-FDG in study of Karbe in 1992 [6]. And this result was recently confirmed by authors of the article [7].

\section{ACKNOWLEDGEMENTS}

Dr. Stanzhevsky A., from Radiology research institute, St. Petersburg, provided radiology counseling.

\section{REFERENCES}

[1] LeDoux, M. and Brady, K. (2003) Secondary cervical dystonia associated with structural lesions of the central nervous system. Movement Disorders, 1, 60-69. doi:10.1002/mds.10301

[2] Soland, V., Evoy, F. and Rivest, J. (1996) Cervical dystonia due to a frontal meningioma. Movement Disorders, 11, 336-337. doi:10.1002/mds.870110323

[3] Tonholo-Silva, E. and Barasnevicius Quagliato, E. (1991) Spasmodic torticollis and frontal meningioma. Arquivos de Neuropsiquiatria, 1, 102-105.

[4] McGeer, E. and McGeer, P. (1995) Pathology of the dystonias. In: Tsui, J. and Calne, D., Eds., Handbook of Dystonia, Taylor \& Francis Inc., New York, 77-101.

[5] Kaste, M., Iivanainen, M. and Juntunen, J. (1981) Brain involvement in spasmodic torticollis. Acta Neurologica Scandinavica, 6, 373-380.

[6] Karbe, H., Holthoff, V., Rudolf, J., Herholz, K. and Heiss, W. (1992) PET demonstrate frontal cortex and basal ganglia hypometabolism in dystonia. Neurology, 42, 1540 -1544. doi:10.1212/WNL.42.8.1540

[7] Belenky, V., Klicenko, O. and Stanzhevsky, A. (2012) Torsion dystonias. Lambert Academic Publishing, Saarbrucken. 